\title{
Advancing Vocabulary Acquisition by Integrating Visual Image and Texts in Writing:
}

\author{
E-learning View
}

\author{
Sariani*, Mutia El Khairat, Yaningsih \\ English Department \\ Politeknik Negeri Padang \\ Padang, Indonesia \\ *sariani@pnp.ac.id, mutia@pnp.ac.id, yaneesulirman@gmail.com
}

\begin{abstract}
Recently, due to the pandemic covid-19 distance learning through online platform becomes the only option for the learners and the teachers to maintain the teaching-learning process. In line with this situation, the aim of this study is to assess the vocabulary acquisition growth on writing task of EFL learners by integrating visual images into the texts. This study was conducted during the supervision of the Final Project (TA) of the last year student at English Department, Politeknik Negeri Padang. A mix method was implemented to accomplish the aim of the study, the Vocabulary Size Test (VST) Monolingual Version A, and semi open-ended interview were used to collect the required data. The VST was performed prior to and after the participant was facilitated by visual images in writing her project, whereas the interview came afterward. The study concluded that integrating visual images into the writing task could make a significant increase on the participant' vocabulary size via e-learning. The innovative learning design in accommodating the needs of EFL learners in writing task could overcome their anxiety in conducting this skill, and improve their vocabulary acquisition. For further research, it is hoped that there would be another analysis on how to provoke learners' independent learning and creativity involving other learning design like audiovisual to accommodate the needs of the learners.
\end{abstract}

Keywords—e-learning, pandemic, visual image, VST, writing

\section{INTRODUCTION}

Learning process, initially, should be done face to face in the classroom using whiteboard, book, and pen with limitation of time. However, regarding to pandemic issue in the beginning of 2020 called COVID-19, this method automatically changed into online learning as a whole process of teaching-learning activities. Therefore, government and all head of higher institutions released circular letter about study at home, as well as Politeknik Negeri Padang (PNP) which have concerned this issue from the beginning it raised. This condition forces teachers to find alternative methods to carry out the teaching-learning process. One of them is writing subject.
Most students found that writing class is a challenging and frustrating at the same time whilst the learning itself should be an interesting activity so that the learning can occur. This states, then, leads to anxiety emersion among learners. Duin and Graves [1] clearly proposed that writing has general and rhetorical objective; that is persuasive which means how to persuade the reader believes what is written in the text. On the other hand, it is widely agreed that learners more focuses on grammar and structure in their writing instead of content and diction. There are many approaches proposed by experts, which depend on the practice and mismatch them with the learning situation. Students' ability can be graded by deciding the topic and time limitation. Looking at the concept, advancing vocabulary acquisition by integrating visual image and text in writing becomes one of the strategies.

Following the phenomenon happened in writing class, it is interesting to integrate visual image and writing on last year students of English Department, Politeknik Negeri Padang (PNP) by using e-learning way since they have to produce writing product as the requirement to graduate from the institution. Even though these students have received knowledge on writing skills for a few specific subjects, the result was not really satisfying. The students tended to concern on their content of the writing instead of the vocabulary itself. Consequently, lack of vocabulary size becomes their hinder in producing a good piece of writing. Regarding to the background information, this research was aimed at assisting student in advancing their vocabulary acquisition by integrating visual image into their writing during the online learning to get the solution for those problems.

\section{A. Vocabulary and Writing}

In designing and learning a language, there should be some aspects to be considered; Learning through meaning-focused input (listening and reading), Learning through meaningfocused output (speaking and writing), Deliberate languagefocused study, and fluency development accross the fours skill [2]. Meaning-focused input focuses more on teaching-learning vocabulary engaged in listening and reading skill, whereas the 
latter meaning-focused output concerns in speaking and writing skills. Vocabulary mastery is considered significant to be learned for these four skills: listening, reading, speaking, and writing. Especially in writing, in order to write an essay, or a composition, good vocabulary which consists of strong vocabulary can enrich the writing and become more influential to the readers [3].

Despite many experts carried out studies in investigating the effects of vocabulary instruction on reading performance, there is a few that focussed on writing performance [1]. Lee [4] analyzed the student' writing after performing reading instruction and comprehension exercise by employing systematic vocabulary instruction. This study investigated the use of vocabulary in delayed writing which was began with reading activity. Nevertheless, previous studies Yonek [5] and Papadopoulou [6] have discussed on this impact of vocabulary instruction on the quality of students' written products. They highlighted three main aspect to be determined in the student' writing performance in accordance with the role of vocabulary: (a) shaping teachers' perceptions of writing quality; (b) predicting students' overall writing performance, and (c) enhancing the quality of students' written compositions" $[6, p$. 35]. A depth of vocabulary size and common language usage are necessary in transferring the idea of the writer into written communication in order to produce quality text, as pointed out by Yonex [5] within her study. She stated that direct and rich instruction of vocabulary can help the student to learn the meaning of familiar word, and indirectly can increase the degree of the student' word knowledge.

\section{B. Integrating Writing with Visual Images}

In most cases, EFL learners face difficulty in term of performing skill. It is because the process in writing requires the learners to be able to reflect their ideas and thoughts and produce them into written form by using accurate language use. Therefore, students are encouraged to learn strategies assisted by their teachers as a facilitator or a coach to generate content and discover a purpose on their writing task that can meet the writer's intention and the readers' needs. Since writing is a complex activity in producing a qualified document, undoubtedly, this kind of task will deliberately stimulate the students' language development by increasing their capability to resolve the problems what writings put in their mind. It can motivates the students in their critical thinking, organizing ideas, and developing the topic into more supporting ideas where at the same time improving the language use within their sentences by considering the aspects of writing: grammar, vocabulary, mechanic, content, and organization $[7,8]$.

As a matter of fact, creating a collaborative environtment between teachers and students is regarded significant in motivating the students to write. It is began when teachers design their lesson plan, and prepare for relevant teaching aids like media (audio, visual, and audiovisual) and/ or technology that can support the implementation of this environment. In accordance with this circumtance, thus teachers are expected to be more creative and innovative in assisting their students to be more creative in finding the ideas, critical in thinking, and developing their vocabulary [9]. The use and choice for integrating an instructional device; visual images with the writing is considered appropriate as this device can arise the interest of the students to link the language to content, encourage learning, and provoke the improvement of their comprehensive linguistic production [7-11]. Observing the provided images can reinforce the students to obtain more information, construct knowledge by evaluating, synthesizing, analyzing their ideas and thoughts prior to write them down. By having this visual aids, teachers can assist their students in clarifying and coordinationg more accurate concepts, engaging them with more concrete study environmet so that while writing they can be more receptive on details [12], starting from drafting to finalizing $[13,14]$.

\section{Online Language Learning}

In recent years, teaching and learning have become very convenient and interesting for both students and teachers due to the widely used of information and communication technology in educational sector. Especially for the students in the range of 18 to 23 year-old, known as Generation $\mathrm{Z}$ who are fully attached to technology [15-19]. The extensive used of the various digital technologies has made the pedagogical strategy applied by teachers shifted into creative, student-centered, open and flexible environtment of online learning. In this online learning, the focus of attention is to establish communicative language teaching and to improve the students' comprehension and ability to master English [20,21]. It is indicated that by integrating appropriate technologies and instructional strategies in language acquisition can decrease the students' anxiety and burden in learning, as they can make use of flexible, interesting, and entertaining materials which depend on the students' regular practice $[15,17,18,22]$. Undoubtedly, this integration can upgrade the efficiency of the language learning itself by facilitating both teachers and students by facilitating them with various online tools referring to the their main functions and features

Many experts in their studies were in line with the effectiveness of using this innovative technoloy-mediated and applied learner-centered environment within the teaching learning process. They agreed that this mode of learning provided the students to fully engaged in knowledge building task [23], guided and encouraged them to concern on their own learning process referred to the authencity and real-life learning activities [20,24,25], changed the way they interact with the course content due to the flexibility, accessibility, and convenience of the learning tools that could increase the quality and the quantity of their pratices, since they had control on their own learning process [26,27]. Besides that this kind of learning also builded up the engangement of the teachers as the facilitator with the students by exchanging views on the given feedback for the students in each stage of learning for clarification [28]

However, a few studies highlihted the challenges faced by this online learning which caused the failure of its 
implementation. The drawbacks were the lack of human interaction, the unorganized and unavailable study materials within the portal used for learning, the absence of hands-on experience in laboratorium and workshop, and the difficulties in self discipline [28]. Solak and Chakir [29] preferred blended learning rather than e-learning as the first mentioned could provide human interaction which for some was exceptionally significant. Attending classes and in person consultation with the teachers could not be underestimated as they could be motivational activities for the students in coping challenges in learning. Like wise, since the learning could not supervised by the teachers encouraged the students to be reluctant to join the online class due to mal practicing (cheating) and procrastinating [30]. In addition, the online unoversities library in some cases were unprepared for this learning platform as students encountered difficulties in accessing the materials needed to support their study. The unavailibility of internet connection was also included within this aspec that made the students apathetic in learning [29].

\section{Methodology}

This reseach employed a mixed method of qualitative and quantitative study which focussed on analyzing language phenomenon investigating certain features or experience in real-life situation [31]; semi open ended-structured interview. Furthermore, a Vocabulary Size Test (VST) Monolingual 20,000 version A was implemented as the quantitative aims. Thus, the phenomenon of writing skill performance at English Department, PNP was discussed in this study and its data was descriptively explained.

\section{A. Participant}

The participant of this study was last year student (6th semester) at English Department, PNP who carried out a final writing project in order to fullfil one of requirements in finishing her study. She received human consent [32] during this research and was allowed to draw back her participation. This student was graded at the intermediate proficiency level (B1) of English competency. She comprehended the points regarding to family, work, school, or leisure related to the topics and able to create simple texts on topics of personal interest. This student was chosen since her project's topic was in accordance with the current research.

\section{B. Instrument}

There were three instruments utilized in this research. The first instrument was VST Monolingual 20,000 Version A, the second one was visual images, the third one was semi open ended-structured interview consisting of five questions. The VST model was adapted from Paul Nation, retrieved from his website http://www.victoria.ac.nz/lals/about/staff/paul-nation), and administered to the participant as the pre- and post-test before and after the writing task began. There were 100 questions with multiple choices in this test which concerned on measuring the productive vocabulary knowledge in writing as well as providing a word form to expressed the meaning.
The second one was the visual image which was integrated to the writing text. The text was assessed by utilizing Analytical Marking Scale for Writing Task scoring profile by Brown [33]. This instrument was used in order to compare the comprehency of participants before and after being facilitated by visual image procedure. The assessment focus on participant performance consisted of five aspects where each of them was weighted differentially. The emphasize wan on first organization (Introduction, Body, and Conclusion) and next content scale, along with grammar, punctuation (spelling and mechanic) and vocabulary.

For triangulation, semi open ended-structured interview was carried out right after the VST post-test performed. In this type of interview, more questions were predetermined than the unstructured interview. The advantage of performing this type of interview that there was sufficient flexibility to allow the interviewee an opportunity to shape the flow of information [34]. The interview was recorded using zoom application and the transcribed into text date. The instrument was aimed at substantiate prior instrument which had been compiled before.

\section{Data Collection and Data Analysis Technique}

The research data were collected from all instruments; the VST result, the writing project of participant and interview transcription between researchers and participant. The VST pre-test' result was collected and regarded as the first main data of this research. It was obtained through email corresponding, and online social media; whatsapp. During the process, participant's writing drafts were compiled and assessed applying Brown's Analytical Marking Scale as the guideline. There were some images integrated into the participant' writing which were in line with the writing' topic. After all treatments had been accomplished, then the participant took another VST Test; post-test, which the result was compared to the first test taken.

It is important to note that the data was also gathered from interviewing the participant. There were five semi open endedstructured questions conveyed in Indonesian to ensure the questions were elaborated as much as possible, where at the same time to lessen the participant' anxiety. These questions were designed to collect valid information regarding to personal point of view and experience considering the visual image treatment to her writing process. The data was obtained through software-based conference; zoom app at the participant' convenience. In order to analyze and performed it, the researchers needed to transfer the data into English. All the data were presented descriptively to elaborate it explanation easily.

\section{RESULTS AND DISCUSSION}

The data were first analyzed from the comparison of preand post-test of Vocabulary Size Test (VST) taken by the participant. The data obtained would be used to determine whether there was an increase on the participant' vocabulary size after facilitating its writing content with visual images. 
The VST result presented in Table 1 shows that there is a significant improvement on the participant' vocabulary knowledge seen from her pre-test total result which is 55 correct, and post-test total result which is 66 correct out of 100 questions.

TABLE I. V VST PRE- AND Post TEST ReSUlt

\begin{tabular}{|l|l|l|l|l|}
\hline \multirow{2}{*}{ Indicator } & \multicolumn{2}{c|}{ Pre-Test } & \multicolumn{2}{c|}{ Post-Test } \\
\cline { 2 - 5 } & $\begin{array}{c}\text { True } \\
\text { Answer }\end{array}$ & $\begin{array}{c}\text { False } \\
\text { Answer }\end{array}$ & $\begin{array}{c}\text { True } \\
\text { Answer }\end{array}$ & $\begin{array}{c}\text { False } \\
\text { Answer }\end{array}$ \\
\hline I (No 1-25) & 18 & 7 & 19 & 6 \\
\hline II (No 26-50) & 15 & 10 & 23 & 2 \\
\hline III (No 51-75) & 9 & 16 & 16 & 9 \\
\hline IV (76-100) & 13 & 12 & 8 & 17 \\
\hline Total & 55 & 45 & 66 & 34 \\
\hline
\end{tabular}

The data obtained was broken down into four indicators which were number of true and false answers ranged in 25 of numbers: I (No 1-25), II (26-50), III (51-75), and IV (76-100). The number of true answer in the post-test result of the 1st part (No 1-25) was slightly higher by 1 number only. Notably, there was substantial growth seen from the 2 nd and 3rd parts (No 26$50)$ by 8 numbers, and (No 51-75) by 7 numbers. Even though the scores achieved on both parts were generally very similar only by 1 number in difference, to some degree, the improvement established by the participants after being facilitated by the visual images can be said highly increased. Despite the fact that an increase occurred in 1st, 2nd, and 3rd part, there was a decrease on the 4th part in comparison on the true answer of pre- and post-test. A general overview made that this last part was consisted of low frequency words such as "dachsun, cadenza, obtrude, panzer, etc." where even though the participant had been suggested to guess the meaning from context, she found difficulty in determining the answer. Perhaps it was due to lack of repeated exposure to the words, which they were insufficiently dropped from the participant' working memory. However, there was no effect on the decrease occurred. Nevertheless, taken from the rising of the total true numbers, there was significant increase on the vocabulary acquisition of the participant, after integrating visual images into her writing. It was interesting to note that, the vocabulary acquisition growth of the participant was presence, apart from the decrease on the total true numbers on her 4th part (No 76-100). The results obtained was in accordance as highlighted by Yonek [5], Papadopoulou [6] in their studies stating that rich instruction in writing outperformed and enhanced the students' vocabulary knowledge and newly learned words' usage.

In addition, from the online interview performed with the participant, there were some pertinent supporting answers from participant revealed. First, the participant used to utilize online and mobile application dictionaries as additional tool in writing process. However, she admitted to never use visual image to assist her in developing the idea and using varied vocabulary in her writing.
TABLE II. EXCERPT 1 OF THE INTERVIEW

I usually use laptop to write, specifically Microsoft word, then I use u dictionary (mobile application dictionary) to get difficult vocabularies for writing process. I prefer the dictionary since it is easier to be used and provide many vocabularies that I need in organizing my writing. However, I still have problem in elaborating my idea. I have limited imagination to be explored even though I have used dictionary with many features and accurate translation ability.

Taken from this excerpt 1 in Table 2 above, it can be highlighted that relying on dictionary was not sufficient enough for her writing process as she faced challenges to concentrate, to make her writing compact/ concise, coherent, and comprehensible in terms of idea and vocabulary usage.

The student also came out with her experience after using visual image as additional media. She pointed out that visual images assisted her to avoid the dullness in her writing. Consequently, the images used had helped her in clarifying the content on given topic by eliciting, explaining, communicating the ideas into the texts. Illustrated in the excerpt 2 in Table 3 below, it can be said that the images also triggered her to find new vocabulary which she never thought before.

\section{TABLE III. EXCERPT 2 OF THE INTERVIEW}

I have never used visual images for writing before, it's my first time.
When I wrote without visual images, I was quite confused and there
was less content that I write at that time. After providing with
images, I have many things to be transferred and described in my
writing. Visual images have helped me to think critically and explore
my idea wider. At the same time, I compiled many new vocabularies
from the images delivered to me during writing experience. I can get
many inspirations and grow one new vocabulary into other new
vocabularies. From one to ten, I'll say ten for utilizing visual image
in writing.

Last finding was quite interesting for the researchers. It was found that the participant in her writing process only focused on grammar instead of vocabulary. In her writing process, she consistently wrote in Indonesia language then converted into English as a consequence of prioritizing grammar. Nevertheless, she agreed that being facilitated with visual images increased her self-confident in writing to clarify complex concepts into a simple and meaningful structure, as pointed out in excert 3 in Table 4 below.

TABLE IV. EXCERPT 3 OF THE INTERVIEW

Personally, first thing that I do in writing is making an outline in Bahasa Indonesia, so I can describe the idea easily. Then, I translate it into English. So that, I can freely develop it, mam. I mean, the English is not confusing. The idea is clearer in Bahasa Indonesia, maam. Grammar has higher level of difficulty than vocabulary.

Based on the interview results higlighted above, besides motivating her in her learning process, the use of visual aids have become beneficial factor for the student to provide 
complex information into her writing, and to increase the number of vocabulary used.

Likewise, Patesan et al. [11] and Ahmed [35] were also agreed that applying the strategy in developing students' vocabulary acquisition was indispensable. Within the excerpts featured above, they seem to reflect the fact that by providing the student with opportunity to have access to authentic input like images can expand the quality of their essay. It is in line with Raoofi et al. [36] argument that by exposing the students to authentic input into their language learning can accelerate the learning itself. These results once again verify the argument made by experts Hashemi and Hadavi [37], Nayan and Krishnasamy [38] regardless the difference on thearticipant educational background stating that students who were facilitated with rich instructions and explicit vocabulary learning strategy could be determined as independent learners who were capable to gradually develop their vocabulary acquisition, self-confidence, involvement, and proficiency.

\section{CONCLUSION AND RECOMMENDATION}

The emergence and development of learning through online platform is necessary in the current pandemic situation in Indonesia. The visual image which was chosen in this study as additional tools of e-learning process, proves that appropriately chosen and designed learning tool has enhanced the learning where at the same time help the teachers to apply authentic materials which are meaningful and close to real life. It is able to provoke and develop learners' achievement. Besides, the finding also shows the improvement on learners' vocabulary acquisition illustrated in their writing tasks. They become more creative, and increase their personal understanding on the task, enrich their writing' content by redirecting their opinions, and perceptions after looking at the images. The interactions between the teachers and the students are still manageable like in the traditional learning, as they communicate effectively by email corresponding, software-based conference application; zoom meeting, and whatsapp. Undoubtedly, integrating visual images into the learners' writing task can be constructive and advance permanent language learning of the learners. To conclude, teachers as the course book writers and curriculum developers may substitute the face-to-face/outdated educational materials with methods of instructional and materials with applicable technology learning aids like audio, visual, audio visual materials, and software package. Alternatively, the learning aids mentioned are foreseen, and can facilitate language learning process to become meaningful and beneficial for the learners' academic development.

\section{ACKNOWLEDGMENT}

We would like to acknowledge Center for Research and Community Service (P3M), Politeknik Negeri Padang (PNP) for providing DIPA Research Grant, year 2020, with the Research Contract No: 258./PL9.1.5/PG/2020, dated 23 Juli 2020.

\section{REFERENCES}

[1] A.H. Duin and M.F. Graves, "Intensive Vocabulary Instruction as a Prewriting Technique,” Read. Res. Q., vol. 22, no. 3, pp. 311-330, 1987.

[2] I.S.P. Nation, Teaching and Learning Vocabulary. Boston: Heinle and Heinle, 2008.

[3] "Vocabulary On Writing In EFL Learners," UKEssays, 2018. [Online]. Retrieved from: https://www.ukessays.com/essays/englishlanguage/vocabulary-on-writing-in-efl-learners-english-languageessay.php [Accessed on: 29-Aug-2020].

[4] S.H. Lee, "ESL learners' vocabulary use in writing and the effects of explicit vocabulary instruction," System, vol. 31, no. 4, pp. 537-561, 2003

[5] L.M. Yonek, The Effects of Rich Vocabulary Instruction on Students Expository Writing. University of Pittsburgh, 2008.

[6] E. Papadopoulou, The Impact of Vocabulary Instruction on the Vocabulary Knowledge and Writing Performance of Third Grade Students. University of Maryland, 2007.

[7] Z. Rao, "Training in Brainstorming and Developing Writing Skills," ELT J., vol. 61, no. 2, pp. 100-106, 2007.

[8] L. Baker, "How Many Words Is a Picture Worth? Integrating Visua Literacy in Language Learning with Photographs," in English Teaching Forum, 2015.

[9] I. Laraswati and S. Suhartono, "The Use of Visual Media in Teaching Writing,” J. English Teach. Res., vol. 1, no. 1, 2016.

[10] G. Shabiralyani, K.S. Hasan, N. Hamad, and N. Iqbal, "Impact of Visual Aids in Enhancing the Learning Process Case Research: District Dera Ghazi Khan,” J. Educ. Pract., vol. 6, no. 19, pp. 226-233, 2015.

[11] M. Patesan, A. Balagiu, and C. Alibec, "Visual Aids in Language Education," in International Conference Knowledge-Based Organization, 2018.

[12] Y. Lan, C. Hung, and H. Hsu, "Effects of Guided Writing Strategies on Students' Writing Attitude Based on Media Richness," TOJET Turkish Online J. Educ. Technol., vol. 10, no. 4, pp. 148-164, 2011.

[13] M. El Khairat and S. Sariani, "Developing Students' Skill in Script Writing for Their Final Project by Applying Guided Writing Task," J. Hum., vol. 9, no. 2, pp. 141-148, 2018.

[14] N. Murray, Writing Essays in English Language and Linguistics: Principles, Tips and Strategies for Undergraduate. United Kingdom: Cambridge University Press, 2012.

[15] A.A. Hussin, "Education 4.0 Made Simple: Ideas For Teaching," Int. J. Educ. Lit. Stud., vol. 6, no. 3, pp. 92-98, 2018.

[16] A.A. Shahroom and N. Hussin, "Industrial Revolution 4.0 and Education,” Int. J. Acad. Res. Bus. Soc. Sci., vol. 8, no. 9, pp. 314-319, 2018.

[17] P. Fisk, "Education $4.0 \ldots$ the future of learning will be dramatically different, in school and throughout life.," 2017. [Online]. Retrieved from: http://www.thegeniusworks.com/2017/01/future-education-youngeveryone-taught-together/ [Accessed on: 18-Mar-2020].

[18] D. Lasse, "Education and Industrial Revolution 4.0," J. Handayani, vol. 10, no. 1, pp. 1-15, 2019.

[19] S. Kozinski, "How generation $Z$ is shaping the change in education," 2017. [Online]. Retrieved from https://www.forbes.com/sites/sievakozinsky/2017/07/24/how generation-Z-is-shaping-the-change-in-education/\#304059746520 [Accessed on: 18-Mar-2020].

[20] H. Cai, "E-learning and English Teaching," in International Conference on Future Computer Supported Education, 2012, pp. 841-846.

[21] A.J. Jabeen, Shazi Shah Thomas, "Effectiveness of Online Language Learning," in World Congress on Engineering and Computer Science, 2015 .

[22] S. Sariani, Y. Yaningsih, and M. El Khairat, "Assessing the Effectiveness of Mobile-Application Technology: A Project-Based Learning,"J. English Educ. Soc., vol. 5, no. 1, pp. 67-73, 2020. 
[23] C. González, "What do University Teachers Think eLearning is Good for in Their Teaching?," J. Stud. High. Educ., vol. 35, no. 1, pp. 61-78, 2010.

[24] N. Mohammadi, V. Ghorbani, and F. Hamidi, "Effects of e-learning on Language Learning," Procedia Comput. Sci., vol. 3, pp. 464-468, 2011.

[25] C.D. Rosell, “Advantages of eLearning for Language Teachers," 2020. [Online]. Retrieved from: https://www.cae.net/advantages-of-elearningfor-language-teachers/ [Accessed on: 13-Apr-2020].

[26] J.X. Montaño-González, "Learning Strategies in Second Language Acquisition," US-China Foreign Lang., vol. 15, no. 8, pp. 479-492, 2017.

[27] J. George-Palilonis and V. Filak, "Blended Learning in the Visual Communications Classroom: Student Reflections on a Multimedia Course,” Electron. J. e-Learning, vol. 7, no. 3, pp. 247-256, 2009.

[28] A. Ghaffari and A. Emami, "Improving Education in Adult through Online Learning,” Life Sci. J., vol. 8, no. 3, 2011.

[29] E. Solak and R. Cakir, "Face to face or E-Learning in Turkish EFL Context," Turkish Online J. Distance Educ., vol. 15, no. 3, pp. 37-49, 2014.

[30] M.A.T. Al-Maqtri, "How Effective is E-learning in Teaching English? : A Case Study,” J. Educ. Hum. Dev., vol. 3, no. 2, pp. 647-669, 2014.
[31] D. Silverman, Qualitative Reseach, Theory, Method and Practice. California: SAGE, 2004.

[32] A. Mackey and S.M. Gass, Second Language Research. Mahwah, New Jersey: Lawrence Erbaulm Associates, Inc. S. A, 2005.

[33] J.D. Brown, "Performance Assessment: Existing Literature and Directions for Research," Second Lang. Stud., vol. 22, no. 2, pp. 91139, 2004.

[34] J. McDonough and S. McDonough, Research Methods for English Language Teachers. Great Britain: Arnold, 1997.

[35] A.A.J.E. Ahmed, "The Role of Vocabulary Learning Strategies in Enhancing EFL Learners' Writing Skills," Int. J. Humanit. Soc. Sci. Educ., vol. 4, no. 8, pp. 41-50, 2017.

[36] S. Raoofi, M. Binandeh, and S. Rahmani, "An Investigation into Writing Strategies and Writing Proficiency of University Students," J. Lang. Teach. Res., vol. 8, no. 1, pp. 191-198, 2017.

[37] Z. Hashemi and M. Hadavi, "Investigation Of Vocabulary Learning Strategies Among EFL Iranian Medical Sciences Students," in 2nd Global Conference On Linguistics And Foreign Language Teaching, LINELT, 2014, pp. 629-637.

[38] S. Nayan and H.N. Krishnasamy, "A Preliminary Study on Vocabulary Learning Strategies Used by the Students from the Faculty of Accountancy," Int. J. Lang. Lit. Linguist., vol. 1, no. 1, pp. 10-14. 